\title{
Monitoring and Landscape Dynamic Analysis of Alpine Wetland Area Based on Multiple Algorithms: A Case Study of Zoige Plateau
}

\author{
Wenlong Li ${ }^{1,2}$, Pengfei Xue ${ }^{1,2, *}$, Chenli Liu ${ }^{1,2}$, Hepiao Yan ${ }^{1,2}$, Gaofeng Zhu ${ }^{3}$ (D) \\ and Yapeng Cao ${ }^{1,2}$ \\ 1 State Key Laboratory of Grassland Agro-Ecosystems, College of Pastoral Agriculture Science and Technology, \\ Lanzhou University, Lanzhou 730020, China; wllee@lzu.edu.cn (W.L.); liuchl18@lzu.edu.cn (C.L.); \\ yanhp19@lzu.edu.cn (H.Y.); caoyp18@lzu.edu.cn (Y.C.) \\ 2 Key Laboratory of Grassland Livestock Industry Innovation, Ministry of Agriculture, Lanzhou University, \\ Lanzhou 730020, China \\ 3 Key Laboratory of Western China's Environmental Systems (Ministry of Education), \\ College of Earth and Environmental Sciences, Lanzhou University, Lanzhou 730020, China; \\ zhugf@lzu.edu.cn \\ * Correspondence: xuepf19@lzu.edu.cn; Tel.: +86-136-6935-3296
}

Received: 12 November 2020; Accepted: 17 December 2020; Published: 19 December 2020

check for updates

\begin{abstract}
As an important part of the wetland ecosystem, alpine wetland is not only one of the most important ecological water conservation areas in the Qinghai-Tibet Plateau region, but is also an effective regulator of the local climate. In this study, using three machine learning algorithms to extract wetland, we employ the landscape ecological index to quantitatively analyze the evolution of landscape patterns and grey correlation to analyze the driving factors of Zoige wetland landscape pattern change from 1995 to 2020. The following results were obtained. (1) The random forest algorithm (RF) performs best when dealing with high-dimensional data, and the accuracy of the decision tree algorithm (DT) is better. The performance of the RF and DT is better than that of the support vector machine algorithm. (2) The alpine wetland in the study area was degraded from 1995 to 2015, whereas wetland area began to increase after 2015. (3) The results of landscape analysis show the decrease in wetland area from 1995 to 2005 was mainly due to the fragmentation of larger patches into many small patches and loss of the original small patches, while the 2005 to 2015 decrease was caused by the loss of many middle patches and the decrease in large patches from the edge to the middle. The 2015 to 2020 increase is due to an increase in the number of smaller patches and recovery of original wetland area. (4) The grey correlation degree further shows that precipitation and evaporation are the main factors leading to the change in the landscape pattern of Zoige alpine wetland. The results are of great significance to the long-term monitoring of the Zoige wetland ecosystem.
\end{abstract}

Keywords: wetland; random forest; Google Earth Engine (GEE); Zoige Plateau; landscape analysis

\section{Introduction}

Wetland provides many important environmental services, including flood storage, drought control, regional climate regulation, erosion control, degradation of environmental pollutants, biodiversity, and habitat [1-6]. As a unique component of the wetland system, alpine wetland on the Qinghai-Tibet Plateau is an important natural resource for the headwaters of the Yangtze and Yellow Rivers [7,8], the first and second largest rivers in China, respectively, and is one of the most important living environments for local Tibetans. However, serious degradation of wetland has been threatening the sustainable development of the regional economy and ecosystem. Wetland degradation is further 
weakening water conservation in the Yangtze and Yellow River headwaters and has been a major cause of the Yellow River's flow reduction and the seasonal drying in recent decades $[9,10]$. Thus, there is an urgent need for advanced technologies and methods to monitor local alpine wetland [11] in order to provide a scientific basis for the protection and management of regional wetland resources.

Remote sensing technology has made wetland monitoring more rapid, efficient, and large-scale [12,13]. The methods of wetland data extraction and classification based on remote sensing mainly include artificial visual interpretation and computer-automated classification. Visual interpretation has high requirements for the interpreter's interpretation experience, and consumes a lot of time and energy, so it is not suitable as an independent classification method. Computer-automated algorithms can be divided into supervised classification and unsupervised classification [14-16]. Many researchers have proved that the supervised classification algorithm based on sample training is much better than unsupervised classification [14-18]. The random forest (RF), support vector machine (SVM), and decision tree (DT) supervision classification algorithms are the three most popular algorithms [17-19] in wetland classification at present, and they each have their own advantages. Considering RF and SVM are more often used on the Google Earth Engine (GEE) platform [20-24], while DT on the traditional platform $[25,26]$, we select the classification method and platform according to most research preferences and further search for the best classification scheme for alpine wetland area.

Wetland degradation can be quantitatively analyzed through the evolution of landscape patterns [27-29]. Landscape indexes can highly concentrate landscape pattern information and reflect some characteristics of its structural composition and spatial allocation. It can be used to quantitatively describe and monitor the changes in landscape spatial structure over time. The landscape pattern index can be divided into patch level index, patch type level index and landscape level index. The patch level index is the basis for calculating other types of landscape indexes. The patch type level index and landscape level index are of great significance for describing and understanding the characteristics of different patch types and the overall landscape pattern in the landscape. The landscape pattern has been changing, which is the result of various factors inside and outside the landscape on different spatio-temporal scales. Identifying the driving factors of landscape pattern change and exploring its driving mechanism is a necessary condition for in-depth understanding of surface landscape evolution [29] and controlling the process of landscape pattern change. Grey correlation degree is a method [30-33] to measure the strength, size, and order of the relationship between things or system factors. In this study, it can analyze the driving factors of wetland landscape pattern change and explain and sort the factors leading to pattern change in order to reveal the change characteristics and rules of the landscape change's driving factors.

Given the background above, this study combined remote sensing images, the landscape ecological index and grey correlation to solve three main questions: (1) what is the best classification scheme for alpine wetland areas? (2) How does the landscape pattern in Zoige wetland change? (3) What are the main factors affecting the change in Zoige landscape pattern?

\section{Materials and Methods}

\subsection{Study Area}

The Zoige Plateau (ZP) $\left(101^{\circ} 36^{\prime} \sim 103^{\circ} 25^{\prime} \mathrm{E}, 32^{\circ} 20^{\prime} \sim 34^{\circ} 06^{\prime} \mathrm{N}\right)$ is a large part of the Qinghai-Tibet Plateau and is a relative subsidence area in the Quaternary strong uplift area, with a total area of $4,247,327 \mathrm{hm}^{2}$ (Figure 1). Its wetland is a typical alpine wetland on the Qinghai-Tibet Plateau's northeast edge [28] and its main classes include marshes, meadow, and flood wetland. The elevation change in this area is $2392-5057 \mathrm{~m}$; the geomorphology is characterized by wide valleys and gentle hills, and the plateau meadow and peat swamp soils are widely developed [34]. The main rivers in the area include the Yellow River and its tributaries, the Heihe and Baihe [7]. The study area is rich in animal and plant resources, with mainly subalpine meadow and swamp vegetation. Animal husbandry is the 
traditional pillar industry in the Zoige region, but due to the unique resources in this area, tourism has become the dominant industry in the area.

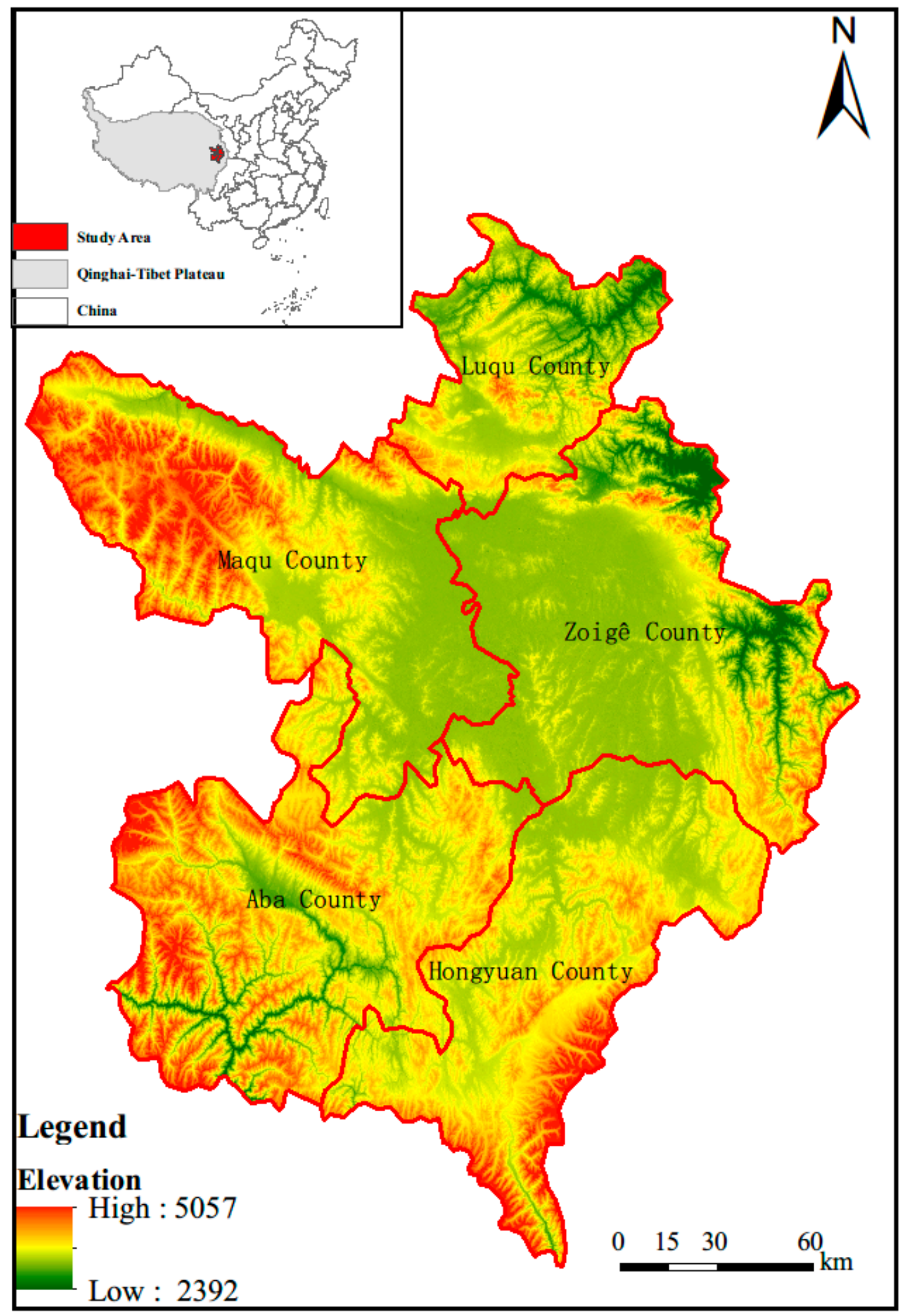

Figure 1. Location of Zoige Plateau (ZP). 


\subsection{Data Preparation}

Our data consisted of two parts: (1) for the satellite imagery analysis, Landsat imagery obtained from United States Geological Survey (USGS, https://www.usgs.gov/) [22] and terrain data with a resolution of $30 \mathrm{~m}$; (2) for the landscape change driver analysis, climate and socioeconomic data from the Data Center of China Meteorological Administration (http://www.cma.gov.cn) and National Statistical Yearbooks, respectively.

\subsubsection{Satellite Imagery Process}

Satellite imagery processing was carried out through two platforms. GEE obtained the relevant images from the integrated database through code for direct online analysis. The traditional method is to download images from the USGS data center for offline analysis. Considering cloud coverage is extensive in this area and a single image cannot satisfy the needs of the experiment, we unified the time limit for data acquisition in the growing season (July-September) $[35,36]$, and the initial filtering defined a maximum cloud-coverage threshold of $30 \%$. The method of multi-temporal dense time stacking $[17,35-38]$ was used to provide a good quality image. All data, pre-processing, post-processing and methods are comprehensively described in Supplementary Materials Text S1.

\subsubsection{Classification Feature Collection}

We extracted the classification features derived from Landsat $5 / 8$ observation (i.e., Band1-5, 7 in Landsat5; Band2-7 in Landsat8) and Digital Elevation Model (DEM) data. Based on the surface reflectance bands, we selected and calculated the following spectral indices: (1) the Normalized Difference Vegetation Index (NDVI) [39,40], the best indicator of vegetation growth status and vegetation coverage; (2) the Normalized Difference Built-up Index (NDBI) [41], the index used to analyze the built-up area; and (3) the Normalized Difference Water Index (NDWI) [42,43] and Modified Normalized Difference Water Index (MNDWI) [44,45], which reflect the surface moisture conditions and play an important role in the extraction of wetland with abundant water information. These indices calculation formulas were summarized in Supplementary Materials Table S1. Terrain features is an important index for land cover classification in alpine areas [46]. Slope [47], aspect [48] and elevation [47] are calculated by DEM to improve classification results.

\subsubsection{Sample Selection}

Most of the articles published in the relevant study area have been combined with the Land-Use and Land-Cover Change (LUCC) classification system, and the features were divided into seven types [49,50]. Considering the small area of farmland and building-land types in the study area, we combined them into artificial land. Six feature types remained: grassland, woodland, wetland, river, artificial land, and unused land (Supplementary Materials Table S2).

Based on extensive field investigations and unmanned aerial vehicle (UAV) data, with reference to Google Earth images from the same period, ArcGIS 10.6 was used to select and generate training samples on Landsat images. Considering the balance of samples, the number of samples is set according to the area proportion of local types [37,51]. The generated samples of 4500 points are "real" and are used for the classification and subsequent classification accuracy evaluation according to the 7:3 ratio $[50,52]$ of training samples to test samples. We selected four kinds of accuracy evaluation indexes used in many studies to evaluate accuracy: overall accuracy, the Kappa coefficient, producer accuracy and user accuracy [52,53].

\subsubsection{Meteorological and Socio-Economic Data}

In order to further explore the relationship between the change in the landscape pattern of Zoige alpine wetland and its influencing factors, the grey correlation analysis was used to analyze the factors affecting the change of wetland landscape pattern. We selected indicators from meteorological and 
socio-economic data to construct an indicator system of landscape pattern change drivers. In this study, meteorological factors (annual temperature, precipitation, and evaporation) were used to analyze the characteristics of alpine wetland area change for ZP. The temperature and precipitation data were derived from the measured data of three meteorological stations (Zoige, Hongyuan, and Maqu) on the ZP. The evaporation data were calculated from the stations' monthly temperature and precipitation data with the following formula:

$$
E=\frac{3100 R}{\left(3100+1.8 R^{2} \exp \left(-\frac{34.4 T}{235.0+T}\right)\right)}
$$

where $E$ is the monthly evaporation $(\mathrm{mm}), R$ is the monthly precipitation $(\mathrm{mm})$, and $T$ is the monthly average temperature $\left({ }^{\circ} \mathrm{C}\right)$.

Observations from three weather stations around the ZP wetland are shown in Figure 2, showing that the average annual temperature has increased significantly over 30 years, with an average temperature increase of about $1.56^{\circ} \mathrm{C}$. From 1990 to 2020, the annual precipitation on the ZP remained stable, and the trend was stable. The average annual precipitation was $682.89 \mathrm{~mm}$ and the average annual evaporation was $268.01 \mathrm{~mm}$.
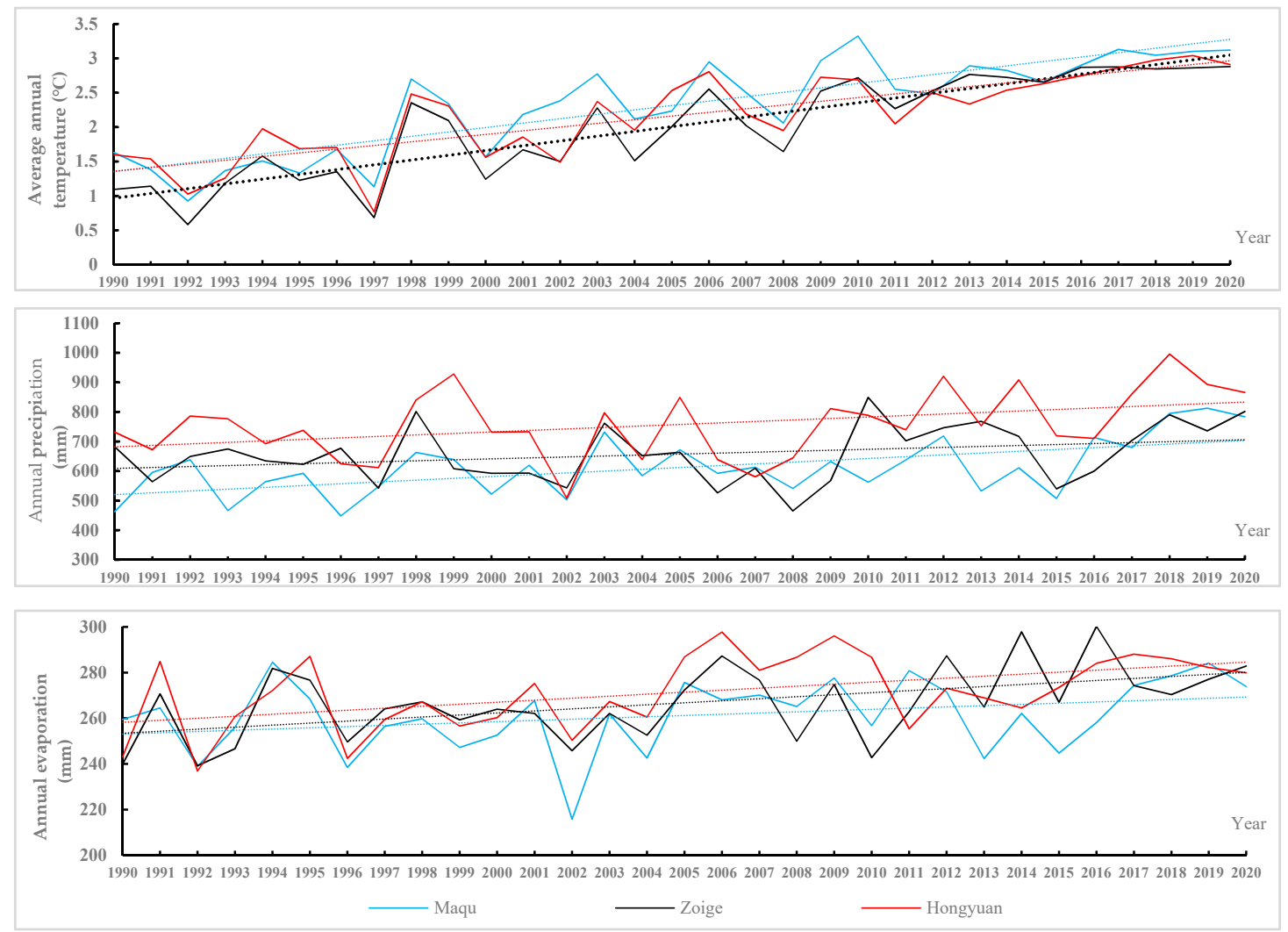

Figure 2. Annual temperature, precipitation, and evaporation at 3 stations, ZP, from 1990 to 2020.

We selected the population, number of livestock, gross domestic product (GDP), primary, secondary, and tertiary industrial output value, and per capita GDP to constitute socio-economic indicators (Table 1). The missing data in 2020 were supplemented by data fitting method. 
Table 1. Socioeconomic data for ZP, from 1995 to 2020.

\begin{tabular}{|c|c|c|c|c|c|c|c|c|}
\hline Year & $\begin{array}{c}\text { Gross } \\
\text { Domestic } \\
\text { Product } \\
\left(\mathbf{1 0}^{4} \text { Yuan }\right)\end{array}$ & $\begin{array}{c}\text { I } \\
\text { Primary } \\
\text { Industry } \\
\left(\mathbf{1 0}^{4} \text { Yuan }\right)\end{array}$ & $\begin{array}{c}\text { II } \\
\text { Secondary } \\
\text { Industry } \\
\left(10^{4} \text { Yuan }\right)\end{array}$ & $\begin{array}{c}\text { III } \\
\text { Tertiary } \\
\text { Industry } \\
\left(\mathbf{1 0}^{4} \text { Yuan }\right)\end{array}$ & $\begin{array}{c}\text { Industrial } \\
\text { Structure \% }\end{array}$ & $\begin{array}{l}\text { Population } \\
\qquad\left(10^{4}\right)\end{array}$ & $\begin{array}{c}\text { Number of } \\
\text { Livestock } \\
\left(10^{4}\right)\end{array}$ & $\begin{array}{l}\text { Per Capita GDP } \\
\left(10^{4} \text { Yuan }\right)\end{array}$ \\
\hline 2000 & 87,261 & 49,939 & 17,953 & 19,369 & $57: 21: 22$ & 22.65 & 295.38 & 0.402 \\
\hline 2005 & 156,655 & 70,133 & 38,493 & 48,029 & $45: 24: 31$ & 25.09 & 336.4 & 0.6481 \\
\hline 2010 & 335,526 & 133,604 & 82,011 & 119,911 & $40: 24: 36$ & 27.84 & 387.22 & 1.2753 \\
\hline
\end{tabular}

\subsection{Methods}

\subsubsection{Calculation Methods of Landscape Indices}

According to the research needs of this study and the ecological significance of each landscape index, the selected landscape indexes include patch area index (the alpine wetland area, WA), patch type proportion index (the wetland percentage in total landscape, WP), landscape change index $(L C I)$, patch number $(\mathrm{PN})$, patch density (PD), landscape shape index (LSI), landscape diversity index (Shannon's Diversity Index, SHDI) and landscape evenness index (Shannon's Evenness Index, SHEI). The landscape index is calculated using Fragstats 4.2 software.

The equations below are used to calculate $W A$ and $W P(\%)$, respectively.

$$
\begin{gathered}
W A=\sum_{j=1}^{n} a_{i j}\left[\frac{1}{10000}\right]\left(h m^{2}\right), \\
W P=\frac{\sum_{j=1}^{n} a_{i j}}{A}(100)
\end{gathered}
$$

where $i$ is the wetland landscape; $j$ as the $\mathrm{PN}, j=1, \ldots, n ; a_{i j}$ refers to the area of the $j$ th patch in the $i$ th patch class, and $A$ refers to the entire area of landscape.

The WP is also called the patch area index of the wetland landscape. It reflects elements and pattern changes in the landscape, and it is used to determine superior landscape elements. A WP value close to 0 indicates that the proportion of wetland in all landscape types is close to 0 ; in contrast, a WP value close to 100 indicates that wetland constitutes $~ 100 \%$ of the landscape.

LCI: defined as the absolute values of change in the land cover types that have the greatest impact on the shape of the landscape [54]. The purpose of this index is to determine the wetland LCI for each of the time intervals.

$$
L C I_{t}=\frac{1}{2} \times\left|W P_{t+1}-W P_{t}\right|
$$

where $L C I_{t}$ is the wetland $L C I$ in each time interval; $W P_{t+1}$ and $W P_{t}$ represents $W P$ during the time interval $t+1$ and $t$.

PN refers to the total number of landscape patches; PD refers to the number of patches per $\mathrm{hm}^{2}$; $\mathrm{PN}$ and PD reflect the degree of landscape fragmentation. The greater the number of patches and landscape patch density, the greater the degree of landscape fragmentation.

LSI: the total boundary length of all patches in the landscape is divided by the square root of the total landscape area, and then multiplied by the correction coefficient of the square. When the patch shape in the landscape is irregular or deviates from the square, the LSI value increases. The formula for LSI is:

$$
L S I=\frac{0.25 E}{\sqrt{A}}
$$

where $E$ is the total length of all patch boundaries in the landscape. 
SHDI: based on information theory, the SHDI is used to measure the complexity of the system structure. The magnitude of landscape diversity reflects the number of landscape elements and the proportion of landscape elements. For this study, SHDI is calculated as follows:

$$
\text { SHDI }=-\sum_{i=1}^{n} P_{i} \ln \left(P_{i}\right)
$$

where $P_{i}$ is the probability of patch type I appearing in the landscape, and $n$ is the total number of patch types in the landscape. The magnitude of diversity depends on two aspects of information: one is the number of patch types (richness), and the other is the uniform distribution of patch types in the area. For a given $n$, when the proportion of all kinds of patch area is the same (that is, $P_{i}=1 / n$ ), SHDI reaches a maximum. In general, with the increase in $S H D I$, the complexity of the landscape structure tends to increase.

SHEI: the evenness index, E, reflects the uneven distribution of patches in the landscape, which is usually expressed by the ratio of the diversity index to its maximum value. The formula for SHEI is:

$$
\text { SHEI }=\frac{H}{H_{M A X}}=\frac{-\sum_{i=1}^{n} P_{i} \ln \left(P_{i}\right)}{\ln (n)}
$$

where $H$ is the SHDI, and $H_{M A X}$ is its maximum. When SHEI tends to be 1 , the uniformity of landscape patch distribution also tends to be the maximum.

\subsubsection{Grey Relational Analysis}

The grey relational analysis method [30,31] based on grey theory can determine the degree of influence of various factors on the development trend of the system, and the formula for grey correlation degree is as follows:

(1) the original data sequence includes characteristic target sequence $\left(x_{0}\right)$ and related factor order $\left(x_{i}\right)$ :

$$
\begin{gathered}
x_{0}=\left(x_{0}(1), x_{0}(2), \ldots, x_{0}(n)\right) \\
x_{i}=\left(x_{i}(1), x_{i}(2), \ldots, x_{i}(n)\right) i=1, \ldots, k
\end{gathered}
$$

(2) calculation of correlation coefficient:

$$
\varepsilon_{i}(k)=\frac{\min _{i}\left(\Delta_{i}(\min )\right)+0.5 \max _{i}\left(\Delta_{i}(\max )\right)}{\left|x_{0}(k)-x_{i}(k)\right|+0.5 \max _{i}\left(\Delta_{i}(\max )\right)}
$$

where $\varepsilon_{i}(k)$ is the relative difference between the sequence of related factors $x_{i}$ and the characteristic target sequence $x_{0}$ at time $k$, called the correlation coefficient of $x_{i}$ to $x_{0}$ at time $k ; 0.5$ is the resolution coefficient; $\min (\Delta i(\min ))$, the minimum difference between the two levels; max $(\Delta i(\max ))$, the maximum difference between the two levels.

(3) The grey correlation calculation is:

$$
r_{i}=\frac{1}{N} \sum_{k=1}^{n} \varepsilon_{i}(k)
$$

where $r_{i}$, the correlation degree between the characteristic target sequence $\left(x_{0}\right)$ and the related factor sequence $\left(x_{i}\right)$. 


\section{Results}

\subsection{Classification Results and Accuracy}

The results of classification and accuracy assessment of land cover types over the six years (1995, 2000, 2005, 2010, 2015 and 2020) using three algorithms are shown in Figure 3 and Table 2. Overall, the RF and DT algorithm have a high accuracy (90.06-94.92\%), while the accuracy of the SVM algorithm is relatively low (84.39-89.62\%). We will not consider the SVM algorithm in the research process. In different years, the differences in the Kappa coefficient and overall accuracy are small between the RF and DT. For individual land cover classes, the classification accuracies are very good overall, and there is little difference from class to class and from year to year. Wetland classification of user accuracy and producer accuracy reached the ideal threshold range. Given that the classification accuracy of the two algorithms is very close to the overall accuracy and the Kappa coefficient, we chose the RF, which has a high accuracy and can analyze the importance of selected variables adopted by the subsequent analysis of the data. Finally, we introduced FROM-GLC version2 (2015_v1) product [14], a widely recognized global 30 m classification products (http://data.ess.tsinghua.edu.cn), to compare with the classification results in our study and further evaluate our classification results. In Figure 4, we chose three wetland areas (A, B and C) to evaluate the classification results in 2015 by visually determining the degree to which the classification results match the image of the growing season. As a whole, the spatial distribution of our classification results was consistent through visual manual inspection. Our study has a finer effect on wetland classification, while the product performs poorly in the classification of wetland in our study area.

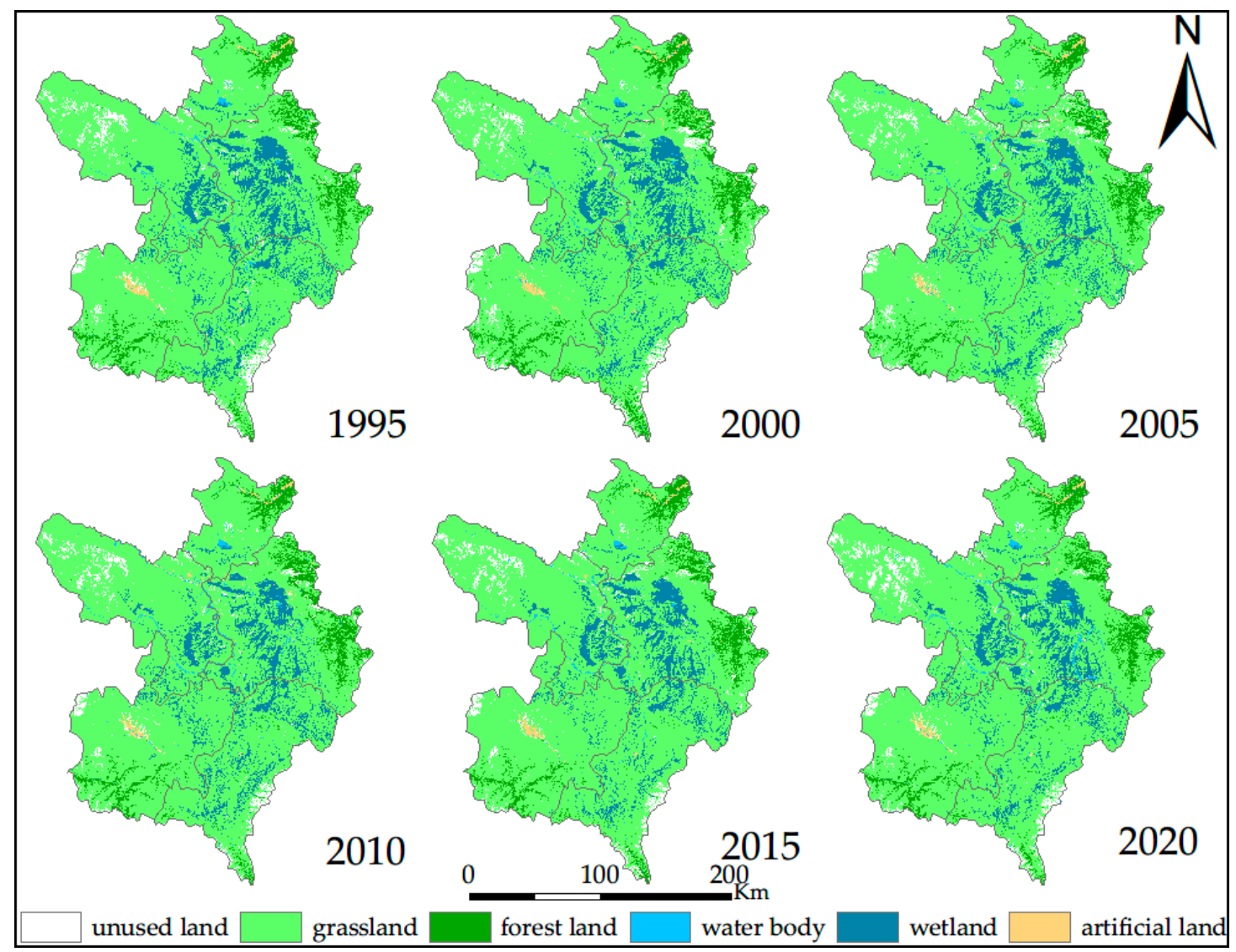

Figure 3. Alpine wetland distribution in ZP for different periods. 
Table 2. Accuracy results for land cover types for 6 years with 3 algorithms.

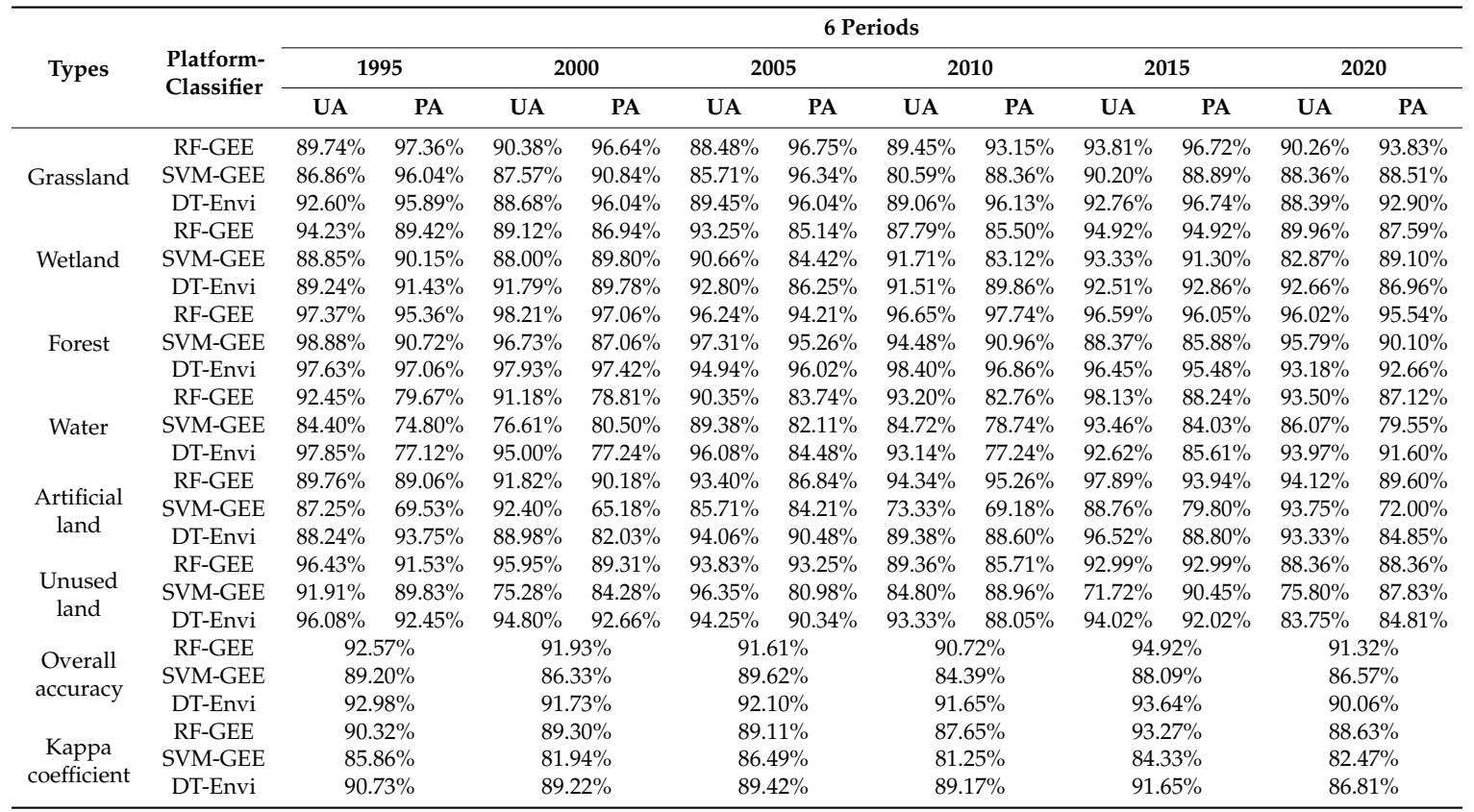

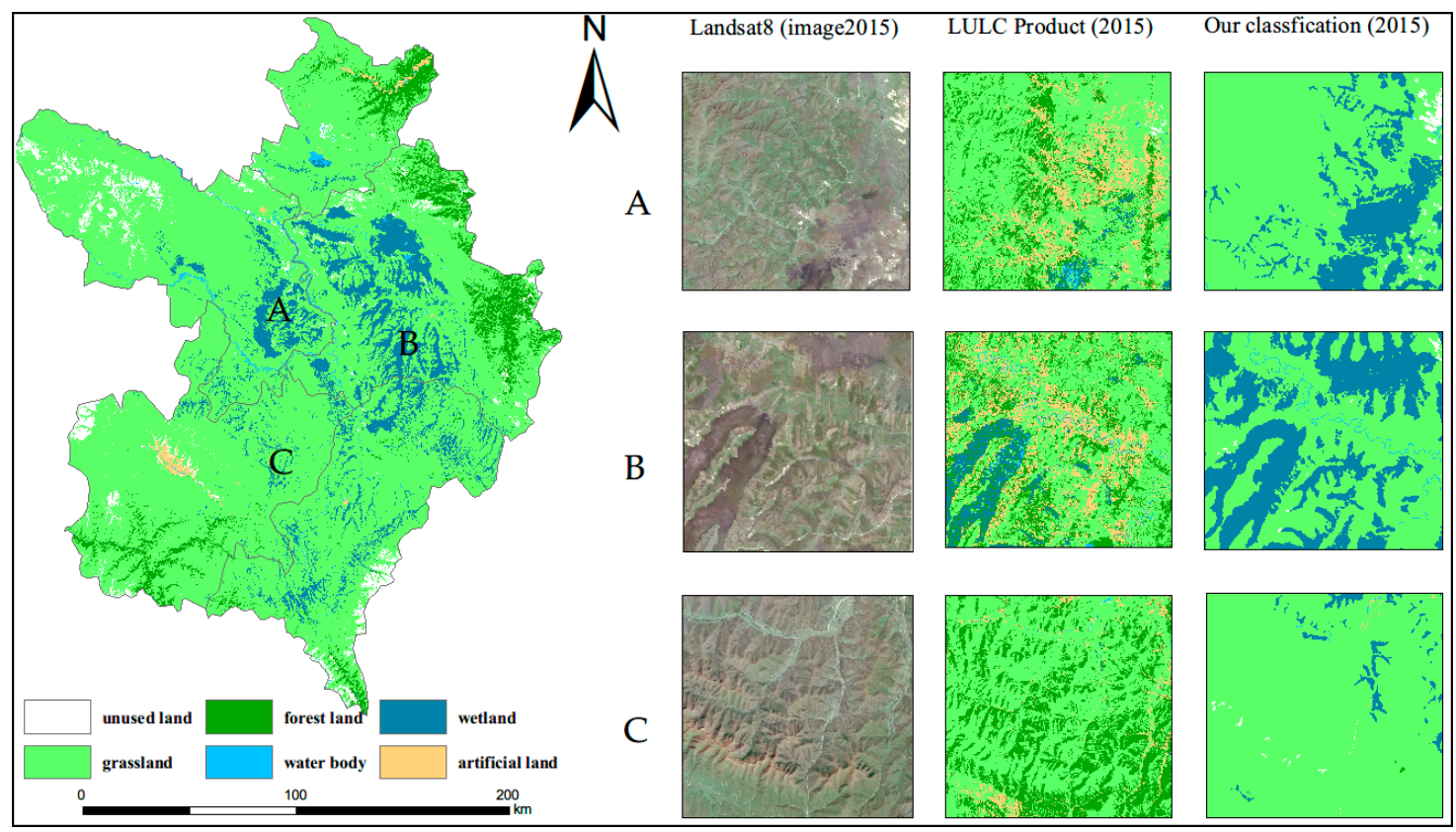

Figure 4. Comparison diagram of classification results (A, B and C refer to three wetland area; left refer to Landsat images in growth season; middle refers to FROM-GLC products; right refers to the classification results of our study).

\subsection{Dynamics Change, from 1995 to 2020}

Tables 3 and 4 show the wetland landscape change including PN, WA, WP and LCI, based on Landsat images of the six years (1995, 2000, 2005, 2010, 2015 and 2020). From 1995 to 2005, the number of wetland patches in the study area increased from 7093 to 9410 , with the biggest rise $(+25.2 \%)$ occurring from 2000 to 2005. From 2005 to 2015, the number of wetland patches in the study area significantly decreased from 9410 to 5703, with the biggest drop (-32.1\%) occurring from 2010 to 2015. The turning point for wetland changes was 2015; wetland area began to increase and PN increased from 5703 to 6323 . The largest changes within the wetland landscape occurred in the period 2000-2005, 
and wetland LCI was 0.200. From 2015 to 2020, the change dynamic was the lowest, and the wetland LCI was 0.125 .

Table 3. Patch number (PN), wetland area (WA), and wetland percentage (WP).

\begin{tabular}{cccc}
\hline Year & $\mathbf{P N} / \mathbf{n}$ & $\mathbf{W A} / \mathbf{h m}^{2}$ & $\mathbf{W P} / \%$ \\
\hline 1995 & $7093\left(^{*}\right)$ & $450,642.87\left(^{*}\right)$ & $10.61\left(^{*}\right)$ \\
2000 & $7515(+5.9 \%)$ & $437,998.77(-2.8 \%)$ & $10.31(-2.8 \%)$ \\
2005 & $9410(+25.2 \%)$ & $420,869.7(-3.9 \%)$ & $9.91(-3.9 \%)$ \\
2010 & $8403(-11.7 \%)$ & $409,675.86(-2.6 \%)$ & $9.65(-2.6 \%)$ \\
2015 & $5703(-32.1 \%)$ & $397,207.44(-3.1 \%)$ & $9.35(-3.1 \%)$ \\
2020 & $6323(+10.9 \%)$ & $407,560.05(+2.7 \%)$ & $9.60(+2.7 \%)$ \\
\hline
\end{tabular}

Note: The $\left(^{*}\right)$ indicate the initial parameters size; the $(\ldots \%)$ indicate the percentage change at time $t+1$ relative to time $t$.

Table 4. Landscape change index (LCI) from 1995 to 2020.

\begin{tabular}{cc}
\hline Time Interval & Wetland LCI \\
\hline $1995-2000$ & 0.150 \\
$2000-2005$ & 0.200 \\
$2005-2010$ & 0.130 \\
$2010-2015$ & 0.150 \\
$2015-2020$ & 0.125 \\
\hline
\end{tabular}

In order to analyze the characteristics of wetland change, the patches were divided into 10 groups according to patch area, a frequency analysis was carried out, and the wetland in six stages was counted according to 10 areas from small to large. As can be seen from Table 5, from 1995 to 2005, the number of wetland patches smaller than $10 \mathrm{hm}^{2}$ showed an obvious increasing trend $(+40.1 \%)$, and the number of patches with sizes of 300 600 $\mathrm{hm}^{2}$ and $600 \sim 1000 \mathrm{hm}^{2}$ showed an obvious decreasing trend $(-29 \%$ and $-25.8 \%$, respectively), indicating some larger patches were broken into many small patches from 1995 to 2005 . From 2005 to 2015 , the number of wetland patches smaller than $10 \mathrm{hm}^{2}$ decreased sharply $(-48.9 \%)$; in fact, the overall reduction in PN was mainly concentrated in the small-patch category. From 2015 to 2020, the number of wetland patches smaller than $10 \mathrm{hm}^{2}$ increased 15\%, while the area distribution of other patches changed slightly.

In order to further analyze the change in wetland area, all the patches were divided into three levels (small, middle, large) according to the size of patch area (i.e., $<1000 \mathrm{hm}^{2}, 1000-10,000 \mathrm{hm}^{2}$, $>10,000 \mathrm{hm}^{2}$ ). The total area of wetland at all levels was counted and the ratio of the increase (or decrease) in the area in the current period compared with that in the previous period was adopted to specifically show the dynamic change of wetland area in different groups. As can be seen from Table 6, from 1995 to 2005, the total area of wetland decreased by $6.6 \%$, the small and large levels decreased by $2.5 \%$ and $15.1 \%$, respectively, and $1000-10,000 \mathrm{hm}^{2}$ increased by $3.5 \%$. This result, combined with other landscape parameters, shows that the decrease in wetland area in this period was mainly due to the fragmentation of larger patches into many small patches and loss of the original small patches. From 2005 to 2015, the total area of wetland decreased by $5.6 \%$, the middle and large levels decreased by $15.3 \%$ and $4.9 \%$, respectively, and small level increased by $2.6 \%$. This shows that the decrease was caused by the loss of many middle patches and the decrease in large patches from the edge to the middle. From 2015 to 2020, the total area of wetland increased by $2.6 \%$, and the small, middle, and large levels increased by $6.1 \%, 1.7 \%$ and $0.4 \%$, respectively. This shows that the increase was caused by increasing in the number of smaller patches and recovery of original wetland area. 
Table 5. PN in different areas of alpine wetland, ZP, from 1995 to 2020.

\begin{tabular}{|c|c|c|c|c|c|c|}
\hline $\begin{array}{l}\text { Number of Patches/n } \\
\text { Area/hm }{ }^{2}\end{array}$ & 1995 & 2000 & 2005 & 2010 & 2015 & 2020 \\
\hline$<10$ & $5579\left(^{*}\right)$ & $5773(+3.5 \%)$ & $\begin{array}{c}7817 \\
(+35.4 \%)\end{array}$ & $\begin{array}{c}6634 \\
(-15.1 \%)\end{array}$ & $\begin{array}{c}4000 \\
(-39.7 \%)\end{array}$ & $\begin{array}{c}4601 \\
(+15.0 \%)\end{array}$ \\
\hline $10 \sim 25$ & $580\left(^{*}\right)$ & $719(+24.0 \%)$ & $622(-13.5 \%)$ & $693(+11.4 \%)$ & $680(-1.9 \%)$ & $701(+3.1 \%)$ \\
\hline $25 \sim 50$ & $361\left(^{*}\right)$ & $372(+3.0 \%)$ & $366(-1.6 \%)$ & $376(+2.7 \%)$ & $387(+2.9 \%)$ & $363(-6.2 \%)$ \\
\hline $50 \sim 100$ & $221\left(^{*}\right)$ & $271(+22.6 \%)$ & $251(-7.4 \%)$ & $290(+15.5 \%)$ & $293(+1.0 \%)$ & $288(-1.7 \%)$ \\
\hline $100 \sim 300$ & $195\left(^{*}\right)$ & $233(+19.5 \%)$ & $224(-3.9 \%)$ & $233(+4.0 \%)$ & $211(-9.4 \%)$ & $234(+10.9 \%)$ \\
\hline $300 \sim 600$ & $73\left(^{*}\right)$ & $60(-17.8 \%)$ & $54(-10 \%)$ & $77(+42.6 \%)$ & $59(-23.4 \%)$ & $57(-3.4 \%)$ \\
\hline $600 \sim 1000$ & $31\left(^{*}\right)$ & $40(+29.0 \%)$ & $23(-42.5 \%)$ & $39(+69.6 \%)$ & $24(-38.5 \%)$ & $26(+8.3 \%)$ \\
\hline $1000 \sim 3000$ & $34\left(^{*}\right)$ & $32(-5.9 \%)$ & $33(+3.1 \%)$ & $42(+27.3 \%)$ & $32(-23.8 \%)$ & $35(+9.4 \%)$ \\
\hline $3000 \sim 10,000$ & $12\left(^{*}\right)$ & $9(-25.0 \%)$ & $13(+44.4 \%)$ & $14(+7.7 \%)$ & $10(-28.6 \%)$ & $11(+10 \%)$ \\
\hline$>10,000$ & $7(*)$ & $6(-14.3 \%)$ & $7(+16.7 \%)$ & $5(-28.6 \%)$ & $7(+40 \%)$ & $7(0)$ \\
\hline
\end{tabular}

Note: The $\left(^{*}\right)$ indicate the initial parameters size; the $(\ldots \%)$ indicate the percentage change at time $t+1$ relative to time $t$.

Table 6. The alpine wetland in the study area consisted of different patches, from 1995 to 2020.

\begin{tabular}{ccccccc}
\hline & $\mathbf{1 9 9 5}$ & $\mathbf{2 0 0 0}$ & $\mathbf{2 0 0 5}$ & $\mathbf{2 0 1 0}$ & $\mathbf{2 0 1 5}$ & $\mathbf{2 0 2 0}$ \\
\hline \multirow{2}{*}{$<1000 \mathrm{hm}^{2}$ (small) } & $131,056.67\left(^{*}\right)$ & $145,567.17$ & $127,784.52$ & $156,258.81$ & $131,129.28$ & $139,128.06$ \\
& & $(+11.0 \%)$ & $(-12.2 \%)$ & $(+22.3 \%)$ & $(-16.1 \%)$ & $(+6.1 \%)$ \\
$1000-10,000 \mathrm{hm}^{2}$ (middle) & $116,713.17\left(^{*}\right)$ & $101,714.04$ & $120,763.89$ & $140,681.34$ & $102,240.45$ & $103,977.55$ \\
& & $(-12.9 \%)$ & $(+18.7 \%)$ & $(+16.5 \%)$ & $(-27.3 \%)$ & $(+1.7 \%)$ \\
$>10,000 \mathrm{hm}^{2}$ (large) & $202,873\left(^{*}\right)$ & $190,717.5$ & $172,321.3$ & $112,735.7$ & $163,837.89$ & $164,454.4$ \\
& & $(-6 \%)$ & $(-16 \%)$ & $(-34.6 \%)$ & $(+45.3 \%)$ & $(+0.4 \%)$ \\
all & $450,642.87\left(^{*}\right)$ & $437,998.77$ & $420,869.7$ & $409,675.86$ & $397,207.44$ & $407,560.05$ \\
& & $(-2.8 \%)$ & $(-3.9 \%)$ & $(-2.7 \%)$ & $(-3.1 \%)$ & $(+2.6 \%)$ \\
\hline
\end{tabular}

Note: The $\left(^{*}\right)$ indicate the initial parameters size; the $(\ldots \%)$ indicate the percentage change at time $t+1$ relative to time $t$.

Combined with Tables 3 and 7, the overall change trends of PN and PD of alpine wetland landscape in ZP from 1995 to 2015 are same. From 1995 to 2005, PN and PD increased, indicating that the number of patches per square kilometer increased and the degree of landscape fragmentation increased. From 2005 to 2015, PN and PD decreased, indicating the number of patches per square kilometer decreased and the degree of landscape fragmentation decreased. In 2020, PN and PD increased again, and the degree of landscape fragmentation increased.

Table 7. Patch density (PD), landscape shape index (LSI), Shannon's Diversity Index (SHDI) and Shannon's Evenness Index (SHEI).

\begin{tabular}{ccccc}
\hline Year & PD & LSI & SHDI & SHEI \\
\hline 1995 & $0.1667\left({ }^{*}\right)$ & $93.3986\left(^{*}\right)$ & $0.3379\left({ }^{*}\right)$ & $0.4875\left({ }^{*}\right)$ \\
2000 & $0.1767(+6.0 \%)$ & $97.421(+4.3 \%)$ & $0.3316(-1.9 \%)$ & $0.4783(-1.9 \%)$ \\
2005 & $0.2212(+25.2 \%)$ & $98.4492(+1.1 \%)$ & $0.3227(-2.7 \%)$ & $0.4656(-2.7 \%)$ \\
2010 & $0.1975(-11.7 \%)$ & $107.8013(+9.5 \%)$ & $0.3169(-1.8 \%)$ & $0.4572(-1.8 \%)$ \\
2015 & $0.1341(-32.1 \%)$ & $88.8969(-17.5 \%)$ & $0.3103(-2.1 \%)$ & $0.4476(-2.1 \%)$ \\
2020 & $0.1549(+15.5 \%)$ & $90.0597(+1.3 \%)$ & $0.3177(+2.3 \%)$ & $0.4584(+2.4 \%)$ \\
\hline
\end{tabular}

Note: The $\left(^{*}\right)$ indicate the initial landscape parameters size; the $(\ldots \%)$ indicate the percentage change at time $t+1$ relative to time $t$.

The change in LSI is shown in Table 7. From 1995 to 2010, the LSI of wetland increased, meaning the landscape shape of wetland tended to be complicated; from 2010 to 2015, the LSI of wetland decreased, and the landscape shape of wetland tended to become homogenized. The LSI of wetland increased slightly (+1.3\%) from 2015 to 2020.

The magnitude of landscape diversity depends on the number of patch types and the uniform distribution of patch types in area. As the SHDI increases, the composition of landscape structure becomes more complex. SHEI reflects the uneven distribution of patches in the landscape. The smaller 
the SHEI, the more uneven the patch distribution. In Table 7, the SHDI and SHEI for alpine wetland on the ZP showed a downward trend from 1995 to 2015, indicating the wetland area continued to decrease, the landscape structure of wetland tends to be simpler, the distribution of patches in area is more uneven, and the distribution of landscape types is more concentrated. From 2015 to 2020 , the SHDI and SHEI showed a slight upward trend $(+2.3 \%$ and $+2.4 \%$, respectively).

\subsection{Results of Dynamic Landscape Changes}

After studying the landscape pattern changes of wetland separately, we noticed the ratio of wetland to other landscapes has been changing dynamically, and we used the results of six phases of classification to make a transfer matrix in order to further explore the transformation relationship between wetland and other features. Table 8 shows that wetland is mainly transformed into grassland, with less transfer to other features; this is mainly related to the landscape distribution of local alpine areas, and the edge of wetland patches is mainly dominated by alpine grassland. With the impact of human activities and climate change, the area of wetland decreased from 1995 to 2015, and wetland continued to transform into grasslands. After 2015, however, the transformation from grassland to wetland becomes the main theme.

Table 8. Transfer matrix of six phases between wetland and other features.

\begin{tabular}{cccccc}
\hline \multirow{2}{*}{ Transfer Type/Time } & \multicolumn{5}{c}{ Change Area (hm $\mathbf{h m}^{\mathbf{}}$} \\
\cline { 2 - 6 } & $\mathbf{1 9 9 5 - 2 0 0 0}$ & $\mathbf{2 0 0 0 - 2 0 0 5}$ & $\mathbf{2 0 0 5 - 2 0 1 0}$ & $\mathbf{2 0 1 0 - 2 0 1 5}$ & $\mathbf{2 0 1 5 - 2 0 2 0}$ \\
\hline Wetland to grassland & $77,471.8$ & $107,182.2$ & 99,318 & $105,216.8$ & $88,084.9$ \\
Grassland to wetland & $65,066.7$ & $89,893.4$ & $89,119.9$ & $92,147.1$ & $97,577.4$ \\
Wetland to others & $80,619.2$ & $109,085.8$ & $101,734.9$ & $106,992.4$ & $89,614.4$ \\
\hline
\end{tabular}

\subsection{Grey Relational Analysis}

The grey correlation degree between the change in wetland landscape pattern and the main climatic factors and human economic activities was calculated. Table 9 shows that annual evaporation and precipitation have the greatest influence on the area of Zoige alpine wetland, followed by the increase in population and livestock and the average annual temperature. Primary, secondary, and tertiary industries also affect the change of landscape pattern of Zoige alpine wetland to some extent.

Table 9. Correlation degree and correlation sequence of wetland area, with influencing factors.

\begin{tabular}{ccccccccc}
\hline $\begin{array}{c}\text { Influencing } \\
\text { Factor }\end{array}$ & $\begin{array}{c}\text { Annual } \\
\text { Evaporation }\end{array}$ & $\begin{array}{c}\text { Annual } \\
\text { Precipitation }\end{array}$ & $\begin{array}{c}\text { Total } \\
\text { Population }\end{array}$ & $\begin{array}{c}\text { Large } \\
\text { Livestock } \\
\text { Inventory }\end{array}$ & $\begin{array}{c}\text { Average } \\
\text { Annual } \\
\text { Temperature }\end{array}$ & $\begin{array}{c}\text { Primary } \\
\text { Industry }\end{array}$ & $\begin{array}{c}\text { Secondary } \\
\text { Industry }\end{array}$ & $\begin{array}{c}\text { Tertiary } \\
\text { Industry }\end{array}$ \\
\hline $\begin{array}{c}\text { Correlation } \\
\text { degree } \\
\text { Sort }\end{array}$ & 0.953 & 0.875 & 0.851 & 0.837 & 0.758 & 0.607 & 0.572 & 0.548 \\
\hline
\end{tabular}

\section{Discussion}

\subsection{Comparison of Classification Results and Analysis of Classification Variable Importance}

In Table 2, we compare the classification accuracy of the three machine learning algorithms in this area. The results show that RF and DT have higher user accuracy, producer accuracy, overall accuracy, and Kappa coefficient, and their performance is better than that of the SVM. Research showed that the classification result of the SVM is ideal in the case of few feature parameters [20]. Based on this, we think the poor performance of the SVM is related to the number of characteristic variables in this study. In addition, we notice there is little difference in accuracy between the RF and the DT. Based on the literature, we know the DT has certain shortcomings compared with the RF [55,56]. This is mainly reflected in the higher requirements for the selection of feature parameters before classification, and the 
selection and understanding of feature parameters directly determine the classification accuracy $[56,57]$. In this experiment, the small difference in accuracy between the two algorithms shows that our selected features basically meet the requirements of classification.

RF is a kind of non-parametric classifier [58] which does not need to consider statistical distribution. Because it may be less sensitive to noise and more efficient in processing highly dimensional data [56], it has become the most popular classifier at present. However, the most important point and the reason for our choice of this algorithm is that it can analyze the importance of feature variables [59] and reduce data redundancy and processing workload while improving the accuracy of the model. We can make full use of this performance to do more in-depth research, such as increasing the number of feature parameters and trying many parameter combinations to obtain the best classification method. In addition, we note that some scholars will give different numbers of characteristic parameters to the two machine learning algorithms (RF and SVM) when classifying [20]. This method avoids the weakness, in that the SVM is not suitable for dealing with high-dimensional data. Nevertheless, it means that the SVM cannot give full play to its advantages. The best solution is to use the RF. In other words, the efficiency of feature variables is maximized by the RF, and these selected feature parameters are used to make the SVM have a better performance.

We calculated the average of the importance score of the six periods for each characteristic variable and sorted them from high to low (Supplementary Materials Table S3). The higher the important score in the image, the greater the influence of this variable on the classification results. In Table 3 , we can see that variables such as elevation, MNDWI, slope, NDVI and NDBI have higher importance scores. The spatial distribution of alpine area is greatly affected by topography and altitude, so the introduction of terrain factors (i.e., elevation and slope) as an important part of characteristic parameters can effectively classify the land types in this area $[46,60]$. MNDWI can maximize the inhibition of vegetation information and highlight water bodies [44], which can distinguish part of the alpine grassland and meadow wetland. NDVI is the best indicator of vegetation coverage and can acquisition a good distinction between vegetation area and non-vegetation area [39]. NDBI is the index used to analyze the built-up area [41]. However, since the main cover types of the study area are alpine grassland and alpine wetland, the importance of this index is less than that of MNDWI and NDVI. The importance of several bands in the image output of Landsat (i.e., Blue, Green, Red, NIR, SWIR1 and SWIR2) is at a medium level, mainly because the previous indexes (i.e., NDVI, MNDWI and NDBI) is calculated by these bands and contains a large amount of original information. MNDWI and NDWI was widely used $[17,61]$ to detect water bodies. However, NDWI does not perform as well as MNDWI in this study, which may be due to the combination of the MNDWI and NDVI, which can reduce the impact of vegetation on water monitoring and easy to have a better performance in alpine wetland with abundant vegetation information and water body information.

\subsection{Analysis of Landscape Dynamics and Drivers of Wetland Changes}

From 1995 to 2015, the alpine wetland on the ZP continued to degrade, and the area decreased year by year. The area of wetland increased from 2015 to 2020 but is still lower than during the 1990s. Combined with frequency and landscape dynamic analysis, the decrease in wetland area from 1995 to 2005 was mainly due to the fragmentation of larger patches into many small patches and the loss of the original small patches. The decrease in wetland area from 2005 to 2015 was due to the loss of many middle patches and the decrease in large patches from the edge to the middle. The increase in wetland area from 2015 to 2020 was due to the increase in the number of smaller patches and the expansion of part of the original patch area.

From 1995 to 2015, the temperature in ZP increased rapidly and precipitation remained stable; this led to a substantial increase in evaporation and insufficient rainfall recharge, and it became difficult for wetland to maintain water levels. In addition, the overall surface water resources in ZP showed a fluctuating downward trend over the past 30 years [62], which caused the area of alpine wetland in ZP to decrease continuously from 1995 to 2015 . The area of alpine wetland in ZP decreased the most from 
2000 to 2005, while the temperature and evaporation increased faster from 2000 to 2005 than during other periods. From 2015 to 2020, the temperature in ZP continued to increase rapidly. The main reason for the increase in wetland area from 2015 to 2020 was the change in climate factors and the decline of livestock carrying capacity. The grey correlation degree further shows that precipitation and evaporation are the main factors leading to the change of landscape pattern of ZP wetland.

We note from Table 3 the area of wetland degradation in 2005 to 2015 decreased compared to 1995 to 2005. Combined with Table 1, this shows that the industrial structure of ZP gradually tends to be stable. This is mainly due to the implementation of the Grassland Law in 2003. The National Ecological Function Regionalization issued by the Ministry of Environment in 2008 divides the ZP into important areas for water conservation. The implementation of the Grassland Law and the release of the National Ecological Function Regionalization have promoted the formulation of a series of ecological protection measures, such as the implementation of the ecological migration project and measures to adjust the policy industrial structure and develop ecotourism. The implementation of these policies has played a certain role in alleviating the degradation of wetland. However, due to the influence of evaporation, annual precipitation, population, and livestock (population and livestock rose from 2005 to 2010, with a downward trend from 2010 to 2015 , but population still increased rapidly overall), the situation of wetland degradation from 2005 to 2015 is still grim.

In Table 1, we can see that the number of livestock in ZP continues to increase, the economic growth of the region has accelerated since 2005, and the proportion of tertiary industry has increased. The development of tourism in this region has promoted the development of local transportation, accommodation, catering, and other service industries, but the rising number of tourists has led to excessive pressure on the population of the region. This will inevitably lead to a sharp increase in the resource consumption in the region, and to the plunder and destruction of wetland resources. Related studies $[63,64]$ have shown the livestock numbers on the ZP have seriously exceeded the actual livestock carrying capacity of the grassland. The average overloading rates of Zoige, Hongyuan, and Aba in 2000 and 2007 were $92 \%$ and $128 \%$, respectively, with $72 \%$ in Maqu County and $71.5 \%$ in Luqu County in 2007. Moreover, the phenomenon of trenching and drainage still exists. There are 17 canals in marshes such as Xiaman Township and Heihe pasture, with a total length of $50.5 \mathrm{~km}$; this turns the swamps of Heihe into grazing land, resulting in wetland degradation. Although the wetland has been restored by measures such as filling and blocking water in more than 20 places since the establishment of the protected area in 2010, due to the decline in groundwater level, the original channel is still draining a large amount of water. Although the industrial structure in ZP tends to be rationalized, it is evident that primary, secondary, and tertiary industries have little influence on the wetland landscape pattern, as seen in Table 9. The adjustment effect of industrial structure is not significant, and the conflict between supply and demand for water resources in this area is still serious, which is not conducive to the protection of alpine wetland. From 2015 to 2020, the population of ZP tended to be stable, annual precipitation increased rapidly, evaporation decreased relatively, and livestock decreased by 238,300 head compared with 2015. In 2019, the local government built a new Zoige wetland science education base to strengthen wetland protection, while a greater emphasis on rational tourism development provided new employment opportunities for the surplus labor force. These measures promote the adjustment of land use and rural industrial structure, resulting in a significant increase in ecological benefits; the interaction of the above factors resulted in a corresponding increase in wetland area by 2020.

Landscape change analysis is an important part of wetland research. Our study on the dynamic change of wetland was all calculated and analyzed by Fragstats 4.2 and we also note scholars in relevant studies [65] used the Landscape Fragmentation Tool v2.0 (LFT) created by the University of Connecticut's Centre for Land Use Education and Research (CLEAR) for producing and visualizing fragmentation metrics. In their study, urban wetland in Khushalsar was taken as the object of study [65]. Four types of landscape were analyzed and revealed using LFT, and the causes of wetland degradation were analyzed accordingly. 


\subsection{Limitations of the Current Study and Platforms Selection}

In order to monitor wetland changes on a long time series scale, some high-resolution images (including the Sentinel imagery) cannot be used in early wetland monitoring. Another dilemma is that the images in this area have been subject to the influence of cloud cover all the year round, and we have adopted the method of multitemporal dense time stacking. Although this method basically removes the influence of cloud cover on the experiment, because the pixel is in an inconsistent time, it also adds uncertainty to the classification process and results. Fortunately, the development of active remote sensing has brought us to a new dawn of understanding, and exploring the integration of optical and radar data to solve the impact of cloud cover on regional monitoring is another development trend in this field [66-68] at present and beyond.

There are always challenges in traditional image analysis, including image downloading and storage, data processing, and preprocessing [69]. Therefore, previous studies have also focused on small areas. In recent years, with the emergence of GEE, great changes have taken place in the research field and depth. GEE brings us many advantages [21]; for example, it allows geospatial analysis to be carried out over the whole space-time continuum, bringing unprecedented processing efficiency. At present, GEE is recognized as a tool with immense computational power. It provides two programming interfaces: JavaScript and Python. Many researchers are constantly improving its functions, and the future GEE will be more powerful. The time and effort spent by the traditional method in small area image processing is still acceptable and it has classification accuracy equal to or even higher than that of GEE, but the better choice is definitely the GEE platform.

\section{Conclusions}

In this study, the dense time stacking of multi-temporal method and growing season Landsat images are used to monitor the dynamic changes in ZP. Through the landscape analysis of three scales, the change direction of the landscape is obtained, and the driving force is analyzed by grey correlation degree.

Our results show the ZP wetland is in a state of degradation during the period from 1995 to 2015 , and the wetland area begins to increase after 2015. The degree of fragmentation of the wetland landscape increased at first and then decreased, and the landscape shape gradually shifted from complexity to homogenization. Landscape diversity continues to decrease, the distribution of large wetland patches is more concentrated, and the area distribution is more uneven. Climate change may be the main factor affecting the proportion of wetland landscape in this area. The RF has the best overall classification effect, and GEE will gradually become an indispensable cloud processing tool.

The study shows that in the future utilization and protection of alpine wetland, we should strengthen reasonable policy guidance, improve the comprehensive management level of wetland reserves, scientifically protect wetland resources, improve the industrial structure of wetland areas, and restrict industrial development. We should promote the development of modern water-saving and energy-saving industries and prevent the destruction of wetland resources by traditional industrial water and land uses.

Supplementary Materials: The following are available online at http://www.mdpi.com/1424-8220/20/24/7315/s1, Table S1: Several popular indices and their formulas; Table S2: Definition of land use classes of classification scheme adopted in this study; Table S3: The order of importance of feature variables in classification; Table S4: Images comprising each study year and the previous and subsequent years composite; Text S1: all data, pre-processing, post-processing, methods.

Author Contributions: W.L. and P.X. had the original idea and designed this study. C.L. and H.Y. were responsible for data processing and analysis. G.Z. and Y.C. contributed to the revision of the manuscript. Writing-review and editing, P.X. and W.L. All authors have read and agreed to the published version of the manuscript. 
Funding: This research was funded by the National Key Research and Development Program of China (2018YFC0406602), the earmarked fund for China Agriculture Research System, the NSFC grants (41471450), the Fundamental Research Fund for the Central Universities (lzujbky-2019-it03, lzujbky-2016-br05), Open project of Qinghai Province Cold Region Restoration Ecology Key Laboratory of Northwest Plateau Biology Institute, Chinese Academy of Sciences (2020-KF-09).

Acknowledgments: We thank the Google Earth Engine platform and develops for their support. We also thank the journal editor and the anonymous reviewers for their useful comments and great efforts on this paper.

Conflicts of Interest: The authors declare no conflict of interest.

\section{References}

1. Rezaee, M.; Mahdianpari, M.; Zhang, Y.; Salehi, B. Deep Convolutional Neural Network for Complex Wetland Classification Using Optical Remote Sensing Imagery. IEEE J. Sel. Top. Appl. Earth Obs. Remote Sens. 2018, 11, 3030-3039. [CrossRef]

2. Agboola, J.I.; Ndimele, P.E.; Odunuga, S.; Akanni, A.; Kosemani, B.; Ahove, M.A. Ecological health status of the Lagos wetland ecosystems: Implications for coastal risk reduction. Estuar. Coast. Shelf Sci. 2016, 183, 73-81. [CrossRef]

3. Castano-Castano, S.; Martinez-Santos, P.; Martinez-Alfaro, P.E. Evaluating infiltration losses in a Mediterranean wetland: Las Tablas de Daimiel National Park, Spain. Hydrol. Process. 2008, 22, 5048-5053. [CrossRef]

4. Eskandari-Damaneh, H.; Noroozi, H.; Ghoochani, O.M.; Taheri-Reykandeh, E.; Cotton, M. Evaluating rural participation in wetland management: A contingent valuation analysis of the set-aside policy in Iran. Sci. Total Environ. 2020, 747, 141127. [CrossRef] [PubMed]

5. Wan, R.R.; Wang, P.; Wang, X.L.; Yao, X.; Dai, X. Modeling wetland aboveground biomass in the Poyang Lake National Nature Reserve using machine learning algorithms and Landsat-8 imagery. J. Appl. Remote Sens. 2018, 12, 046029. [CrossRef]

6. Boys, C.A.; Williams, R.J. Succession of fish and crustacean assemblages following reinstatement of tidal flow in a temperate coastal wetland. Ecol. Eng. 2012, 49, 221-232. [CrossRef]

7. Dong, Z.; Hu, G.; Yan, C.; Wang, W.; Lu, J. Aeolian desertification and its causes in the Zoige Plateau of China's Qinghai-Tibetan Plateau. Environ. Earth Sci. 2010, 59, 1731-1740. [CrossRef]

8. Zhang, Y.; Wang, G.; Wang, Y. Changes in alpine wetland ecosystems of the Qinghai-Tibetan plateau from 1967 to 2004. Environ. Monit. Assess. 2011, 180, 189-199. [CrossRef]

9. Liu, L.; Cao, W.; Shao, Q.; Huang, L.; He, T. Characteristics of Land Use/Cover and Macroscopic Ecological Changes in the Headwaters of the Yangtze River and of the Yellow River over the Past 30 Years. Sustainability 2016, 8, 237. [CrossRef]

10. Wang, X.; Chen, R.; Yang, Y. Effects of Permafrost Degradation on the Hydrological Regime in the Source Regions of the Yangtze and Yellow Rivers, China. Water 2017, 9, 897. [CrossRef]

11. Zhi, W.; Ji, G. Constructed wetlands, 1991-2011: A review of research development, current trends, and future directions. Sci. Total Environ. 2012, 441, 19-27. [CrossRef] [PubMed]

12. McCarthy, M.J.; Colna, K.E.; El-Mezayen, M.M.; Laureano-Rosario, A.E.; Mendez-Lazaro, P.; Otis, D.B.; Toro-Farmer, G.; Vega-Rodriguez, M.; Muller-Karger, F.E. Satellite Remote Sensing for Coastal Management: A Review of Successful Applications. Environ. Manag. 2017, 60, 323-339. [CrossRef] [PubMed]

13. Adeli, S.; Salehi, B.; Mahdianpari, M.; Quackenbush, L.J.; Brisco, B.; Tamiminia, H.; Shaw, S. Wetland Monitoring Using SAR Data: A Meta-Analysis and Comprehensive Review. Remote Sens. 2020, 12, 2190. [CrossRef]

14. Gong, P.; Li, X.C.; Zhang, W. 40-Year (1978-2017) human settlement changes in China reflected by impervious surfaces from satellite remote sensing. Sci. Bull. 2019, 64, 756-763. [CrossRef]

15. Gong, P.; Wang, J.; Yu, L.; Zhao, Y.; Zhao, Y.; Liang, L.; Niu, Z.; Huang, X.; Fu, H.; Liu, S.; et al. Finer resolution observation and monitoring of global land cover: First mapping results with Landsat TM and ETM+ data. Int. J. Remote Sens. 2013, 34, 2607-2654. [CrossRef]

16. Friedl, M.A.; McIver, D.K.; Hodges, J.C.F.; Zhang, X.Y.; Muchoney, D.; Strahler, A.H.; Woodcock, C.E.; Gopal, S.; Schneider, A.; Cooper, A.; et al. Global land cover mapping from MODIS: Algorithms and early results. Remote Sens. Environ. 2002, 83, 287-302. [CrossRef] 
17. Han, X.; Chen, X.; Feng, L. Four decades of winter wetland changes in Poyang Lake based on Landsat observations between 1973 and 2013. Remote Sens. Environ. 2015, 156, 426-437. [CrossRef]

18. Ge, J.; Meng, B.; Liang, T.; Feng, Q.; Gao, J.; Yang, S.; Huang, X.; Xie, H. Modeling alpine grassland cover based on MODIS data and support vector machine regression in the headwater region of the Huanghe River, China. Remote Sens. Environ. 2018, 218, 162-173. [CrossRef]

19. Han, X.; Feng, L.; Hu, C.; Chen, X. Wetland changes of China's largest freshwater lake and their linkage with the Three Gorges Dam. Remote Sens. Environ. 2018, 204, 799-811. [CrossRef]

20. Rapinel, S.; Mony, C.; Lecoq, L.; Clément, B.; Thomas, A.; Hubert-Moy, L. Evaluation of Sentinel-2 time-series for mapping floodplain grassland plant communities. Remote Sens. Environ. 2019, 223, 115-129. [CrossRef]

21. Tamiminia, H.; Salehi, B.; Mahdianpari, M.; Quackenbush, L.; Adeli, S.; Brisco, B. Google Earth Engine for geo-big data applications: A meta-analysis and systematic review. ISPRS J. Photogramm. Remote Sens. 2020, 164, 152-170. [CrossRef]

22. Gorelick, N.; Hancher, M.; Dixon, M.; Ilyushchenko, S.; Thau, D.; Moore, R. Google Earth Engine: Planetary-scale geospatial analysis for everyone. Remote Sens. Environ. 2017, 202, 18-27. [CrossRef]

23. Zhang, D.-D.; Zhang, L. Land Cover Change in the Central Region of the Lower Yangtze River Based on Landsat Imagery and the Google Earth Engine: A Case Study in Nanjing, China. Sensors 2020, $20,2091$. [CrossRef]

24. Hao, B.; Ma, M.; Li, S.; Li, Q.; Hao, D.; Huang, J.; Ge, Z.; Yang, H.; Han, X. Land Use Change and Climate Variation in the Three Gorges Reservoir Catchment from 2000 to 2015 Based on the Google Earth Engine. Sensors 2019, 19, 2118. [CrossRef]

25. Friedl, M.A.; Brodley, C.E. Decision tree classification of land cover from remotely sensed data. Remote Sens. Environ. 1997, 61, 399-409. [CrossRef]

26. Xu, M.; Watanachaturaporn, P.; Varshney, P.K.; Arora, M.K. Decision tree regression for soft classification of remote sensing data. Remote Sens. Environ. 2005, 97, 322-336. [CrossRef]

27. Wang, C.; Yang, W.; Zhu, Y.; Ren, Y. Analysis of the impact of ancient city walls on urban landscape patterns by remote sensing. Landsc. Ecol. Eng. 2020. [CrossRef]

28. Bai, J.-H.; Lu, Q.-Q.; Wang, J.-J.; Zhao, Q.-Q.; Ouyang, H.; Deng, W.; Li, A.-N. Landscape pattern evolution processes of alpine wetlands and their driving factors in the Zoige Plateau of China. J. Mt. Sci. 2013, 10, 54-67. [CrossRef]

29. Tang, J.; Li, Y.; Cui, S.; Xu, L.; Ding, S.; Nie, W. Linking land-use change, landscape patterns, and ecosystem services in a coastal watershed of southeastern China. Glob. Ecol. Conserv. 2020, 23, e01177. [CrossRef]

30. Huang, C.-Y.; Hsu, C.-C.; Chiou, M.-L.; Chen, C.-I. The main factors affecting Taiwan's economic growth rate via dynamic grey relational analysis. PLoS ONE 2020, 15, e0240065. [CrossRef]

31. Almetwally, A.A. Multi-objective Optimization of Woven Fabric Parameters Using Taguchi-Grey Relational Analysis. J. Nat. Fibers 2020, 17, 1468-1478. [CrossRef]

32. Xie, W.; Ma, Y.; Li, S.; Zhang, S.; Ruan, L.; Yang, M.; Shi, W.; Zhang, H.; Zhang, L. Optimizing soil dissolved organic matter extraction by grey relational analysis. Pedosphere 2020, 30, 589-596. [CrossRef]

33. Li, B.; Wu, Q.; Zhang, W.; Liu, Z. Water resources security evaluation model based on grey relational analysis and analytic network process: A case study of Guizhou Province. J. Water Process Eng. 2020, 37, 101429. [CrossRef]

34. Shen, G.; Yang, X.C.; Jin, Y.X.; Xu, B.; Zhou, Q.B. Remote sensing and evaluation of the wetland ecological degradation process of the Zoige Plateau Wetland in China. Ecol. Indic. 2019, 104, 48-58. [CrossRef]

35. White, J.C.; Wulder, M.A.; Hobart, G.W.; Luther, J.E.; Hermosilla, T.; Griffiths, P.; Coops, N.C.; Hall, R.J.; Hostert, P.; Dyk, A.; et al. Pixel-Based Image Compositing for Large-Area Dense Time Series Applications and Science. Can. J. Remote Sens. 2014, 40, 192-212. [CrossRef]

36. Flood, N. Seasonal Composite Landsat TM/ETM plus Images Using the Medoid (a Multi-Dimensional Median). Remote Sens. 2013, 5, 6481-6500. [CrossRef]

37. Huang, H.; Chen, Y.; Clinton, N.; Wang, J.; Wang, X.; Liu, C.; Gong, P.; Yang, J.; Bai, Y.; Zheng, Y.; et al. Mapping major land cover dynamics in Beijing using all Landsat images in Google Earth Engine. Remote Sens. Environ. 2017, 202, 166-176. [CrossRef]

38. Roy, D.P.; Ju, J.C.; Kline, K.; Scaramuzza, P.L.; Kovalskyy, V.; Hansen, M.; Loveland, T.R.; Vermote, E.; Zhang, C.S. Web-enabled Landsat Data (WELD): Landsat ETM plus composited mosaics of the conterminous United States. Remote Sens. Environ. 2010, 114, 35-49. [CrossRef] 
39. Huete, A.; Didan, K.; Miura, T.; Rodriguez, E.P.; Gao, X.; Ferreira, L.G. Overview of the radiometric and biophysical performance of the MODIS vegetation indices. Remote Sens. Environ. 2002, 83, 195-213. [CrossRef]

40. Jiang, W.; Yuan, L.; Wang, W.; Cao, R.; Zhang, Y.; Shen, W. Spatio-temporal analysis of vegetation variation in the Yellow River Basin. Ecol. Indic. 2015, 51, 117-126. [CrossRef]

41. Zha, Y.; Gao, J.; Ni, S. Use of normalized difference built-up index in automatically mapping urban areas from TM imagery. Int. J. Remote Sens. 2003, 24, 583-594. [CrossRef]

42. Huang, C.; Chen, Y.; Zhang, S.; Wu, J. Detecting, Extracting, and Monitoring Surface Water from Space Using Optical Sensors: A Review. Rev. Geophys. 2018, 56, 333-360. [CrossRef]

43. McFeeters, S.K. The use of the normalized difference water index (NDWI) in the delineation of open water features. Int. J. Remote Sens. 1996, 17, 1425-1432. [CrossRef]

44. $\mathrm{Xu}, \mathrm{H}$. Modification of normalised difference water index (NDWI) to enhance open water features in remotely sensed imagery. Int. J. Remote Sens. 2006, 27, 3025-3033.

45. Langat, P.K.; Kumar, L.; Koech, R. Monitoring river channel dynamics using remote sensing and GIS techniques. Geomorphology 2019, 325, 92-102. [CrossRef]

46. Wang, H.; Liu, C.; Zang, F.; Yang, J.; Li, N.; Rong, Z.; Zhao, C. Impacts of Topography on the Land Cover Classification in the Qilian Mountains, Northwest China. Can. J. Remote Sens. 2020, 46, 344-359. [CrossRef]

47. Farr, T.G.; Rosen, P.A.; Caro, E.; Crippen, R.; Duren, R.; Hensley, S.; Kobrick, M.; Paller, M.; Rodriguez, E.; Roth, L.; et al. The shuttle radar topography mission. Rev. Geophys. 2007, 45, RG2004. [CrossRef]

48. Srinet, R.; Nandy, S.; Padalia, H.; Ghosh, S.; Watham, T.; Patel, N.R.; Chauhan, P. Mapping plant functional types in Northwest Himalayan foothills of India using random forest algorithm in Google Earth Engine. Int. J. Remote Sens. 2020, 41, 7296-7309. [CrossRef]

49. Shen, G.; Yang, X.; Jin, Y.; Luo, S.; Xu, B.; Zhou, Q. Land Use Changes in the Zoige Plateau Based on the Object-Oriented Method and Their Effects on Landscape Patterns. Remote Sens. 2019, 12, 14. [CrossRef]

50. Liu, C.; Li, W.; Zhu, G.; Zhou, H.; Yan, H.; Xue, P. Land Use/Land Cover Changes and Their Driving Factors in the Northeastern Tibetan Plateau Based on Geographical Detectors and Google Earth Engine: A Case Study in Gannan Prefecture. Remote Sens. 2020, 12, 3139. [CrossRef]

51. Berhane, T.M.; Costa, H.; Lane, C.R.; Anenkhonov, O.A.; Chepinoga, V.V.; Autrey, B.C. The Influence of Region of Interest Heterogeneity on Classification Accuracy in Wetland Systems. Remote Sens. 2019, 11, 551. [CrossRef]

52. Damtea, W.; Kim, D.; Im, S. Spatiotemporal Analysis of Land Cover Changes in the Chemoga Basin, Ethiopia, Using Landsat and Google Earth Images. Sustainability 2020, 12, 3607. [CrossRef]

53. Ji, H.; Li, X.; Wei, X.; Liu, W.; Zhang, L.; Wang, L. Mapping 10-m Resolution Rural Settlements Using Multi-Source Remote Sensing Datasets with the Google Earth Engine Platform. Remote Sens. 2020, 12, 2832. [CrossRef]

54. Krajewski, P.; Solecka, I.; Mrozik, K. Forest Landscape Change and Preliminary Study on Its Driving Forces in Sleza Landscape Park (Southwestern Poland) in 1883-2013. Sustainability 2018, 10, 4526. [CrossRef]

55. Teluguntla, P.; Thenkabail, P.S.; Oliphant, A.; Xiong, J.; Gumma, M.K.; Congalton, R.G.; Yadav, K.; Huete, A. A 30-m landsat-derived cropland extent product of Australia and China using random forest machine learning algorithm on Google Earth Engine cloud computing platform. ISPRS J. Photogramm. Remote Sens. 2018, 144, 325-340. [CrossRef]

56. Belgiu, M.; Dragut, L. Random forest in remote sensing: A review of applications and future directions. ISPRS J. Photogramm. Remote Sens. 2016, 114, 24-31. [CrossRef]

57. Na, X.; Zhang, S.; Li, X.; Yu, H.; Liu, C. Improved Land Cover Mapping using Random Forests Combined with Landsat Thematic Mapper Imagery and Ancillary Geographic Data. Photogramm. Eng. Remote Sens. 2010, 76, 833-840. [CrossRef]

58. Breiman, L. Random forests. Mach. Learn. 2001, 45, 5-32. [CrossRef]

59. Ma, L.; Fu, T.; Blaschke, T.; Li, M.; Tiede, D.; Zhou, Z.; Ma, X.; Chen, D. Evaluation of Feature Selection Methods for Object-Based Land Cover Mapping of Unmanned Aerial Vehicle Imagery Using Random Forest and Support Vector Machine Classifiers. ISPRS Int. J. Geo-Inf. 2017, 6, 51. [CrossRef]

60. Karlson, M.; Gålfalk, M.; Crill, P.; Bousquet, P.; Saunois, M.; Bastviken, D. Delineating northern peatlands using Sentinel-1 time series and terrain indices from local and regional digital elevation models. Remote Sens. Environ. 2019, 231, 111252. [CrossRef] 
61. Wang, X.; Xiao, X.; Zou, Z.; Chen, B.; Ma, J.; Dong, J.; Doughty, R.B.; Zhong, Q.; Qin, Y.; Dai, S.; et al. Tracking annual changes of coastal tidal flats in China during 1986-2016 through analyses of Landsat images with Google Earth Engine. Remote Sens. Environ. 2020, 238, 110987. [CrossRef]

62. Pekel, J.F.; Cottam, A.; Gorelick, N.; Belward, A.S. High-resolution mapping of global surface water and its long-term changes. Nature 2016, 540, 418-422. [CrossRef] [PubMed]

63. Qiu, P.; Wu, N.; Luo, P.; Wang, Z.; Li, M. Analysis of dynamics and driving factors of wetland landscape in Zoige, Eastern Qinghai-Tibetan Plateau. J. Mt. Sci. 2009, 6, 42-55. [CrossRef]

64. Lei, G.; Li, A.; Zhang, Z.; Bian, J.; Hu, G.; Wang, C.; Nan, X.; Wang, J.; Tan, J.; Liao, X. The Quantitative Estimation of Grazing Intensity on the Zoige Plateau Based on the Space-Air-Ground Integrated Monitoring Technology. Remote Sens. 2020, 12, 1399. [CrossRef]

65. Rashid, I.; Aneaus, S. Landscape transformation of an urban wetland in Kashmir Himalaya, India using high-resolution remote sensing data, geospatial modeling, and ground observations over the last 5 decades (1965-2018). Environ. Monit. Assess. 2020, 192, 635. [CrossRef] [PubMed]

66. Mo, Y.; Zhong, R.; Sun, H.; Wu, Q.; Du, L.; Geng, Y.; Cao, S. Integrated Airborne LiDAR Data and Imagery for Suburban Land Cover Classification Using Machine Learning Methods. Sensors 2019, 19, 1996. [CrossRef] [PubMed]

67. Tavares, P.A.; Santos Beltrao, N.E.; Guimaraes, U.S.; Teodoro, A.C. Integration of Sentinel-1 and Sentinel-2 for Classification and LULC Mapping in the Urban Area of Belem, Eastern Brazilian Amazon. Sensors 2019, 19, 1140. [CrossRef] [PubMed]

68. Wu, Q.; Zhong, R.; Zhao, W.; Song, K.; Du, L. Land-cover classification using GF-2 images and airborne lidar data based on Random Forest. Int. J. Remote Sens. 2018, 40, 2410-2426. [CrossRef]

69. Tobón-Marín, A.; Cañón Barriga, J. Analysis of changes in rivers planforms using google earth engine. Int. J. Remote Sens. 2020, 41, 8654-8681. [CrossRef]

Publisher's Note: MDPI stays neutral with regard to jurisdictional claims in published maps and institutional affiliations.

(C) 2020 by the authors. Licensee MDPI, Basel, Switzerland. This article is an open access article distributed under the terms and conditions of the Creative Commons Attribution (CC BY) license (http://creativecommons.org/licenses/by/4.0/). 